\title{
May Cervical Length Predict Miscarriage Associated With Invasive Procedures for Prenatal Diagnosis?
}

\author{
Emine Demirel, MD, PhD ${ }^{1 *}$; Emre Ekmekci, MD, PhD², Sefa Kelekci, MD, PhD ${ }^{1}$
}

'Department of Obstetrics and Gynecology, Maternal-Fetal Medicine Unit, Faculty of Medicine, Izmir Katip Celebi University, Izmir, Turkey

2 Department of Obstetrics and Gynecology, Maternal-Fetal Medicine Unit, Sanliurfa Education and Research Hospital, Sanliurfa, Turkey

\begin{abstract}
Objectives: Prenatal invasive tests are being used for the diagnosis of fetal aneuploidies. Fetal loss is the major complication of invasive procedures with varying proportions. In this study, we aimed to determine the predictivity of cervical length (CL) in terms of miscarriage associated with diagnostic prenatal invasive procedures that are performed in two separate centers.

Methods: This is a prospective study of 1168 women with singleton pregnancies who have undergone prenatal invasive procedures for fetal karyotyping from January 2012 to May 2018, in the maternal-fetal medicine units of two separate centers. Out of 1168 subjects, 1052 singleton pregnant women who had undergone prenatal invasive procedures were included in the study and 116 women who had voluntary induced abortion after the procedures due to major fetal abnormalities were excluded. Transvaginal cervical lengths were provided to all the patients, right after the procedures. Miscarriage occurred within two weeks after the procedure was evaluated as a complication of the procedure. The demographic data of the patients with ongoing pregnancies and miscarriage rates were compared with patients with all other variables.

Results: Amniocentesis was performed on 883 patients (83.9\%) after 16 weeks of gestation. Chorionic villus sampling (CVS) was carried out transabdominally on 93 patients (8.84\%) between 11-14 weeks and cordocentesis was performed on 76 patients (7.2\%) due to advanced gestational ages. Two miscarriages occurred within two weeks after the procedures. One of them was at the 13th week of pregnancy that had undergone CVS and the other one was at the 18th week that had undergone amniocentesis. Procedure-related miscarriage rate was calculated as $0.19 \%$. Mean CL was $29 \mathrm{~mm}$ in the miscarriage group and $32.7 \pm 4.7 \mathrm{~mm}$ in the ongoing pregnancy group.

Conclusion: Cervical length may not be a good prognostic marker for miscarriage associated with diagnostic prenatal invasive procedures.
\end{abstract}

\section{Introduction}

Appropriate fetal cells for karyotype analysis during pregnancy can be obtained from amniotic fluid by amniocentesis after 16 weeks of gestation, or from the placental tissue by chorionic villus sampling (CVS) in the first trimester, as well as from the fetal blood by cordocentesis at the advanced gestational ages. The most crucial complication of these prenatal invasive procedures is the procedure-related miscarriage. The distinct rate of pregnancy loss associated with amniocentesis is uncertain, but the American College of Obstetricians and Gynecologists (ACOG) Practice Bulletin reported 1/300-500 risks of miscarriage associated with amniocentesis after the 15th week of pregnancy [1]. In a systematic review, similar miscarriage rates within 14 days of transabdominal CVS and amniocentesis are reported as 0.7 and 0.6 percent, respectively [2]. Cordocentesis carries approximately 1.4 to $1.9 \%$ risk of miscarriage rate $[3,4]$.

Several risk factors have been proposed for procedure-associated miscarriage such as operator experience, gestational age, sampling route, and the number of tapping; but the cause of procedure-related miscarriage remains unknown $[5,6]$. A short cervix, conventionally defined as shorter than $25 \mathrm{~mm}$, obtained by transvaginal route in the mid-trimester of pregnancy, is a powerful risk factor for spontaneous preterm delivery. $\mathrm{CL}$ has been proved as an effective predictor of spontaneous preterm birth for singleton gestations $[7,8]$. Additionally, there is evidence that the measurement of the cervix at the 11-14 weeks scan can help to establish the risk of preterm birth $[9,10]$. Based on this data, it leads to the idea whether $\mathrm{CL}$ may predispose procedure-related miscarriage just as it predicts preterm birth.

In this study, we aimed to determine the predictivity of $\mathrm{CL}$ in terms of miscarriage associated with diagnostic prenatal invasive procedures performed in two separate maternal-fetal medicine units.

\section{Materials and Methods}

This prospective cohort study was carried out in the Department of Obstetrics and Gynecology, Maternal - Fetal Medicine Unit, School of Medicine, Izmir Katip Celebi University, Izmir, Turkey and the Department of Obstetrics and Gynecology, Maternal - Fetal Medicine Unit, Sanliurfa Education and Research Hospital, Sanliurfa, Turkey between January 2012 and May 2018. Both hospitals are referral centers. Approval for this study was obtained by the Department of Obstetrics and Gynecology Clinical Academic Board. The study design was in accordance with the Declaration of Helsinki for medical research involving human subjects and conformed to the Committee on Publication Ethics Guidelines.

A total of 1168 diagnostic prenatal invasive procedures on singleton pregnancies were performed. Out of this, 1052 singleton pregnant women who had undergone diagnostic prenatal invasive procedures were included in the study and 116 patients who had induced abortion after the procedures were excluded. Other exclusion criteria were the following: multiple pregnancies planned cervical cerclage, uterine mullerian anomalies, and the absence of perinatal outcome information.

Positive screening in the first and second trimester screening tests was described in the case of a higher risk than the cut-off with $5 \%$ false positive rate. Appropriate diagnostic prenatal invasive procedures were performed according to the various gestational ages.

Transvaginal sonographic $\mathrm{CL}$ measurement was performed on all the patients, right after the invasive procedures. Transvaginal $\mathrm{CL}$ measurements were provided by Voluson E6 and Voluson E8 (General Electric, Milwaukee, WI, USA) devices according to Fetal Medicine Foundation (FMF) Guidelines [11] in a dorsal lithotomy position. All ultrasound examinations were carried out by only two maternal-fetal medicine specialists (SK 
and $\mathrm{EE}$ ), both with Fetal Medicine Foundation Certificate accreditation for competence in cervical assessment. A sagittal view of the cervix was obtained without applying cervical pressure with the ultrasound probe, and then the calipers were used to measure the linear distance between the triangular area of echodensity at the external os and the V-shaped notch at the internal os. When the cervix was curved, two or more segments were measured. The shortest cervical length was recorded. Miscarriages occurred within two weeks after the procedures were evaluated as procedure-related. All patients who have undergone diagnostic invasive procedures were followed up for procedure-related loss for two weeks.

For all cases, the procedure-related characteristics (indication, technique, the diameter of the needle, and the number of needle entries), as well as maternal characteristics (maternal age, gestational age during the procedure, $\mathrm{CL}$ ), obstetric history, pregnancy outcome, and fetal karyotype results were recorded (Table 1 and 2).

The main outcome measure was the procedure-related loss in accordance with the first and mid-trimester CL. The demographic data of patients with ongoing pregnancies and miscarriages were compared with the patients with all other variables.

Statistical analyses were performed using MedCalc Statistical Software (MedCalc Software, Ostend, Belgium). Statistical data was reported descriptively due to a small number of miscarriages. Categorical variables were given as median (minimum-maximum). $\mathrm{P}<0.05$ was considered statistically significant.

Table 1. Maternal and Pregnancy Characteristics of Study Population

\begin{tabular}{|l|c|c|}
\hline \multicolumn{1}{|c|}{ Parameters } & Miscarriage (N=2) & Ongoing Pregnancy (N=1050) \\
\hline Maternal Age (mean \pm SD) & $31 \pm 6$ & $31.1 \pm 7.1$ \\
\hline Gravity, median & 1 & 2 \\
\hline Parity, median & 1 & 1 \\
\hline Abortion, median & 0 & $17 \pm 2.2$ \\
\hline Gestational Age (mean \pm SD) & $16.8 \pm 2.7$ & $613(58.3)$ \\
\hline Indication & & $235(22.3)$ \\
\hline \multicolumn{1}{|c|}{ Positive Screening, N (\%) } & $2(100)$ & $198(18.8)$ \\
\hline \multicolumn{1}{|c|}{ Fetal Anomaly, N (\%) } & $0(0)$ & 0 \\
\hline Maternal Anxiety, N (\%) & $0(0)$ & \\
\hline
\end{tabular}

$\mathrm{SD}$, standard deviation.

\begin{tabular}{|c|c|c|}
\hline Variables & Pregnancy Loss $(\mathrm{N}=2)$ & Ongoing Pregnancy $(\mathrm{N}=1050)$ \\
\hline Cervical Length $(\mathrm{mm}$, mean $\pm \mathrm{SD})$ & $27.9 \pm 5.8$ & $32.7 \pm 4.7$ \\
\hline \multicolumn{3}{|l|}{ Invasive Procedure } \\
\hline CVS, N (\%) & $1(50)$ & $92(8.7)$ \\
\hline AS, N (\%) & $1(50)$ & $882(84)$ \\
\hline CS, N (\%) & $0(0)$ & $76(7.3)$ \\
\hline \multicolumn{3}{|l|}{ Number of Tap } \\
\hline One Tap, N (\%) & $2(100)$ & $1018(96.9)$ \\
\hline Two Taps, N (\%) & $0(0)$ & $32(3.1)$ \\
\hline \multicolumn{3}{|l|}{ Side of Tapping } \\
\hline Upper Quadrant, N (\%) & $2(100)$ & $920(87.6)$ \\
\hline Lower Quadrant, N (\%) & $0(0)$ & $130(12.4)$ \\
\hline \multicolumn{3}{|l|}{ Karyotype Results } \\
\hline Normal, N (\%) & $2(100)$ & $969(92.3)$ \\
\hline Abnormal, N (\%) & $0(0)$ & $81(7.7)$ \\
\hline
\end{tabular}

AS, Amniocentesis; CS, Cordocentesis; CVS, Chorionic villus sampling; SD, standard deviation.

\section{Results}

Baseline maternal and pregnancy characteristics of the study population are shown in Table 1. The mean gestational age of 1052 singleton pregnancies at the procedure was $17 \pm 2.2$ weeks (11-32). Median gravida was 2 (1-9) and parity was 1 (0-7) (Table 1). Amniocentesis was performed on 883 patients $(83.9 \%)$ after 16 weeks gestation, CVS was carried out transabdominally on 93 patients (8.84\%) between 11-14 weeks, and cordocentesis was performed on 76 patients (7.2\%) (Table 2).

Fetal karyotypes were normal on 971 pregnancies (92.3\%) and were abnormal on 81 patients (7.7\%). Mean CL was $32 \pm 4.6 \mathrm{~mm}(18-51 \mathrm{~mm})$. We had a total of two miscarriages. One of them was at the 13th week of pregnancy that had undergone CVS at the 12th week of pregnancy due to increased nuchal translucency and the other one was at the18th week of pregnancy that has undergone amniocentesis due to the positive screening on second trimester screening test at the 16th week of pregnancy.
Karyotypes were normal in both miscarriages. CL of the CVS patient was $28 \mathrm{~mm}$ and that of the amniocentesis patient was $30 \mathrm{~mm}$. Procedure-related rate was $0.19 \%$. Mean CL was $29 \mathrm{~mm}$ in the miscarriage group and $32.7 \pm 4.7 \mathrm{~mm}$ in the ongoing pregnancy group (Table 2 ).

No significant difference was found between the pregnancies concluded with miscarriage and the ongoing pregnancies, with respect to the following variables: the size of the needle, needle insertion location, test indication, number of insertions, and karyotyping results.

\section{Discussion}

In this prospective multicenter study, CL was taken during 11-24 weeks gestations. The small number of patients complicated with miscarriage was not enough to make a statistical analysis and to validate the conclusion. In general, however, the miscarriage rate after diagnostic invasive procedures was very low. Therefore, it was difficult to perform a random- 
ized clinical trial with a large sample size. But, our results demonstrated that $C L$ was within normal limits in the patients complicated with miscarriage after diagnostic invasive procedures. We did not detect any association between procedure-related miscarriage and CL.

The bulk of evidence from randomized trials suggests that the rate of spontaneous loss attributed to the amniocentesis procedure ranges from 0.06 to 1.0 percent $[2,12,13]$. The data for CVS are equally inconsistent, partly because of different methods used to obtain chorionic villi (transabdominal compared with transvaginal). Transabdominal CVS and amniocentesis appear to be associated with similar rates of miscarriage. Miscarriage rate within 14 days of transabdominal CVS was 0.7 percent, and 0.6 percent for amniocentesis, while it was almost twofold higher (1.4 to 1.9 percent) for cordocentesis than in controls $[2,4,14]$. In our study population, procedure-related miscarriage rates were similar to these results for transabdominal CVS and amniocentesis, as $1.07 \%$ and $0.11 \%$, respectively. Some of the factors that may influence the miscarriage risk after procedures are multiple needle insertions, needle size, indication of procedure, and the technical skills of the operator. Presence of fetal anomalies as an indication for diagnostic amniocentesis is associated with increased risk of fetal loss (odds ratio: 8.5) [6]. In this study population, we had only two miscarriages and karyotypes of them were normal.

Repeated attempts during the procedure also proved risk factors for miscarriage $[6,13]$. Although it is unlikely that needle size is a significant factor, a study reporting the highest miscarriage rate used a $19 \mathrm{G}$ needle, while another study reporting a significantly lower miscarriage rate with $0.2 \%$ used $21 \mathrm{G}[15,16]$. Based on the data for multiple insertions, it may be appropriate to use a benchmark, as $2 \%$ of amniocentesis procedures and $5.5 \%$ of transabdominal CVS procedures [2]. In our study, more than one needle puncture was required only in $3 \%$ of all patients. $21 \mathrm{G}$ needle was used for amniocentesis and cordocentesis. $18 \mathrm{G}$ needle was used for chorionic villous sampling. All procedures were done by experienced maternal-fetal medicine specialists.

Recent studies have suggested that the first trimester CL screening with maternal characteristics could be feasible for prediction of early spontaneous preterm birth with $54.8 \%$ detection rate. Studies focusing on the length of endocervical canal have reported that median CL is between 31-34 mm during 11-13 weeks that varies with maternal characteristics such as height and race $[17,18]$. Although the pathophysiology of spontaneous preterm birth is multifactorial, the $C L$ evaluation in the second trimester has been shown to be one of the best predictors in low-risk population with the risk of preterm birth being inversely associated with that $[8,19]$. In a recent prospective cohort study, significantly increased risk of preterm delivery is reported in case of short CL in low risk population [20]. Also, it has been shown that a low-risk population corresponds to low proportions of women with a short cervix in the second trimester [20]. In our study, CLs were 28 and $30 \mathrm{~mm}$, respectively, in the first and second trimesters in procedure related miscarriages, and the Mean $\mathrm{CL}$ was $32.7 \mathrm{~mm}$ in ongoing pregnancies. We could not conclude statistically evidenced result with this data, but the cervical length was within normal limits at both miscarriages.

A possible limitation to our study was that the transvaginal CL measurement was performed right after all prenatal invasive procedures. Possible uterine contractions depending on the procedure could affect the cervix measurement. But, we recorded the shortest CL during measurements to prevent this. An important strength of the study is the prospective design with high intra- and inter-observer reliability for CL measurement [21]. Additionally, this is the first study evaluating the efficacy of $\mathrm{CL}$ on the prediction of miscarriage attributed to the prenatal invasive procedures.

\section{Conclusion}

In this prospective clinical trial, despite the small study population, we can make a conclusion that CL screening at the first trimester and at the second trimester may show poor performance for prediction of procedural dependent miscarriage. That's why $C L$ evaluation may not be a prognostic factor for miscarriage due to all types of prenatal invasive procedures.

\author{
Article Information \\ * Correspondence: Emine Demirel, MD, PhD \\ Department of Obstetrics and Gynecology, Maternal-Fetal Medicine Unit, \\ Faculty of Medicine, Izmir Katip Celebi University, Izmir, Turkey. \\ Email: er_em.dr@hotmail.com
}

Received: Jun. 12, 2018; Accepted: Aug. 06, 2018; Published: Oct. 01, 2018

DOI: $10.24983 /$ scitemed.rwh.2018.00083

Copyright $\odot 2018$ The Author(s). This is an open-access article distributed under the terms of the Creative Commons Attribution 4.0 International License (CC-BY).

\section{Funding: None}

\section{Conflict of Interest: None}

\section{Disclosures}

This paper is an extension of the electronic poster that has been presented under abstracts of 26th World Congress on Ultrasound in Obstetrics and Gynecology, Rome, Italy, 24-28 September 2016.

\section{Keywords}

Cervical length; prenatal invasive test; transvaginal ultrasound.

\section{References}

1. American College of Obstetricians and Gynecologists. ACOG Practice Bulletin No. 88, December 2007. Invasive prenatal testing for aneuploidy. Obstet Gynecol 2007;110(6):1459-1467.

2. Mujezinovic F, Alfirevic Z. Procedure-related complications of amniocentesis and chorionic villous sampling: a systematic review. $O b$ stet Gynecol 2007;110(3):687-694.

3. Ghidini A, Sepulveda W, Lockwood CJ, Romero R. Complications of fetal blood sampling. Am J Obstet Gynecol 1993;168(5):1339-1344.

4. Tongsong T, Wanapirak C, Piyamongkol W, et al. Second-trimester cordocentesis and the risk of small for gestational age and preterm birth. Obstet Gynecol 2014;124(5):919-925.

5. Antsaklis A, Daskalakis G, Papantoniou N, Michalas S. Fetal blood sampling--indication-related losses. Prenat Diagn 1998;18(9):934940.

6. Bakker M, Birnie E, Robles de Medina P, Sollie KM, Pajkrt E, Bilardo CM. Total pregnancy loss after chorionic villus sampling and amniocentesis: a cohort study. Ultrasound Obstet Gynecol 2017;49(5):599606.

7. Hernandez-Andrade $\mathrm{E}$, Romero $\mathrm{R}, \mathrm{Ahn} \mathrm{H}$, et al. Transabdominal evaluation of uterine cervical length during pregnancy fails to identify a substantial number of women with a short cervix. J Matern Fetal Neonatal Med 2012;25(9):1682-1689.

8. Berghella V, Baxter JK, Hendrix NW. Cervical assessment by ultrasound for preventing preterm delivery. Cochrane Database Syst Rev 2009;8(3):CD007235.

9. Kagan KO, To M, Tsoi E, Nicolaides KH. Preterm birth: the value of sonographic measurement of cervical length. BJOG 2006;113 Suppl 3:52-56.

10. Sonek J, Shellhaas C. Cervical sonography: a review. Ultrasound Obstet Gynecol 1998;11(1):71-78.

11. The Fetal Medicine Foundation. Cervical Assessment. Available at: https://fetalmedicine.org/cervical-assessment-1.

12. Eddleman KA, Malone FD, Sullivan L, et al. Pregnancy loss rates after midtrimester amniocentesis. Obstet Gynecol 2006;108(5):1067-1072.

13. Andreasen E, Kristoffersen K. Incidence of spontaneous abortion after amniocentesis: influence of placental localization and past obstetric and gynecologic history. Am J Perinatol 1989;6(2):268-273. 
14. Smidt-Jensen S, Permin M, Philip J, et al. Randomised comparison of amniocentesis and transabdominal and transcervical chorionic villus sampling. Lancet 1992;340(8830):1237-1244.

15. Rousseau O, Boulot $P$, Lefort $G$, et al. Amniocentesis before 15 weeks' gestation: technical aspects and obstetric risks. Eur J Obstet Gynecol Reprod Biol 1995;58(2):127-130.

16. Antsaklis A, Papantoniou N, Xygakis A, Mesogitis S, Tzortzis E, Michalas S. Genetic amniocentesis in women 20-34 years old: associated risks. Prenat Diagn 2000;20(3):247-250.

17. Souka AP, Papastefanou I, Michalitsi V, et al. Cervical length changes from the first to second trimester of pregnancy, and prediction of preterm birth by first-trimester sonographic cervical measurement. J Ultrasound Med 2011(7);30:997-1002.

18. Greco E, Gupta R, Syngelaki A, Poon LC, Nicolaides KH. First-trimes- ter screening for spontaneous preterm delivery with maternal characteristics and cervical length. Fetal Diagn Ther 2012;31(3):154-161.

19. Heath VC, Southall TR, Souka AP, Elisseou A, Nicolaides KH. Cervical length at 23 weeks of gestation: prediction of spontaneous preterm delivery. Ultrasound Obstet Gynecol 1998;12(5):312-317.

20. Wulff CB, Rode L, Rosthøj S, Hoseth E, Petersen OB, Tabor A. Transvaginal sonographic cervical length in first and second trimesters in a low-risk population: a prospective study. Ultrasound Obstet Gynecol 2018;51(5):604-613. P

21. Stein W, Hellmeyer L, Schmidt S, Tekesin I. Intraobserver and interobserver reliability of transvaginal cervical length measurements and quantitative ultrasound tissue characterization of the cervix in the second and third trimester of pregnancy. Ultraschall Med 2011;32 Suppl 2:E169-E174. 